\title{
Forced Expiratory Volume in 0.2 Second
}

National Cancer Institute

\section{Source}

National Cancer Institute. Forced Expiratory Volume in 0.2 Second. NCI Thesaurus. Code C139248.

The volume of air that can be forcibly exhaled during the first 0.2 second following maximal inhalation. 